\section{Cenário de Práticas para a Formação Universitária: O Olhar dos Estudantes}

\author{
Scenario of Practices Aimed at University Education: The \\ Students' Perspectives
}

\section{RESUMO}

A Educação Universitária tem como desafio atual o aprimoramento de suas práticas pedagógicas. $\mathrm{O}$ objetivo do presente trabalho foi conhecer os valores e significados atribuídos, por estudantes do curso de Nutrição da USP, às suas experiências de extensão universitária. Trata-se de um estudo de abordagem qualitativa, utilizando-se o grupo focal como técnica de coleta de dados. Foram realizados cinco grupos, divididos entre as principais atividades realizadas: Empresa Júnior, Iniciação Científica, Associação Atlética, Clínica de Nutrição e Jornada Universitária. Verifica-se que os estudantes consideraram que cada atividade colabora com o desenvolvimento de competência ou habilidade profissional específica. Dentre elas, destacam-se: autonomia, autoconfiança, comunicação interpessoal, comunicação social, trabalho em equipe, visão ampliada dos problemas e das necessidades sociais, conhecimento técnico e teórico específico, atenção integral, contato com a realidade profissional, entre outras. Conclui-se que as atividades de extensão universitária contribuem tanto para que, especificamente na área da saúde, os projetos pedagógicos sejam flexíveis para a incorporação dessas atividades.

Palavras-chave: Ensino Superior. Competências Profissionais. Nutrição. Extensão Universitária.

\section{ABSTRACT}

Higher Education currently faces the challenge of improving its pedagogical practices. The aim of this study was to survey what values and meanings students of Nutrition of the University of São Paulo (USP) ascribe to their experiences with university extension. This is a qualitative study that uses focus groups as a technique to collect data. Five groups were set up according to the most performed activities: Junior Company, Scientific Initiation, Athletic Association, Nutrition Clinic, and the University

\section{ANA Maria \\ Cervato-Mancuso, \\ Nadine Marques \\ NUnes e \\ Elisabete Agrela de \\ ANDRADE \\ Universidade de São Paulo. Faculdade de Saúde Pública, São Paulo, Brasil}


Experience (Jornada Universitária, in Portuguese), an interdisciplinary health care project. We found that students felt that each activity contributes to the development of expertise or specific professional skills, which include autonomy, self-confidence, interpersonal communication, social communication, teamwork, a wider perspective on social issues and needs, specific technical and theoretical knowledge, comprehensive care, and contact with professional reality, among others. We conclude that especially in the health care area, university extension activities are a valuable contribution and educational projects should be flexible enough as to incorporate those activities.

Keywords: Higher Education. Professional Skills. Nutrition. University Extension.

\section{INTRODUÇÃO}

Diante do contexto de avanços tecnológicos e da adequação das formas de ensino ao mundo do trabalho, a Educação Superior vem sendo convidada a reinventar suas práticas pedagógicas, para possibilitar oportunidades de aprendizagem e para produzir ou transformar as experiências que cada sujeito tem de si mesmo como propõe [6].

$\mathrm{Na}$ Universidade de São Paulo não tem sido diferente. Em recentes esforços para atualizar suas intervenções, foram propostas práticas de "cultura e extensão" para alunos da graduação. Os sujeitos dessas ações são, prioritariamente, jovens imersos em uma sociedade competitiva e incentivadora do consumo como forma de pertencimento e vivem suas tensões: por um lado vislumbrados pelo próprio potencial de terem conquistado uma vaga na universidade pública e, por outro, preocupados com suas possíveis fragilidades em relação à entrada no mercado de trabalho.

$\mathrm{O}$ foco que se empreitou aqui foi de conhecer um pouco mais o que esses jovens pensavam a respeito de suas experiências universitárias de cultura e extensão. Desta forma, apresentamos este texto como parte de uma pesquisa realizada entre estudantes matriculados no curso de Nutrição da Faculdade de Saúde Pública da Universidade de São Paulo, que teve como objetivo identificar e descrever as atividades de cultura e extensão no âmbito da Universidade, bem como avaliar o significado dessa participação.

\section{que é Cultura e Extensão}

Para a USP, a extensão universitária é "um processo que articula o ensino e a pesquisa de forma a viabilizar a interação transformadora entre a universidade e a sociedade e que a relação entre ensino, pesquisa e extensão universitária enriquece o processo pedagógico, favorecendo a socialização do saber acadêmico e estabelecendo uma dinâmica que contribui para a participação da comunidade na vida universitária" [13].

Em consonância, Ponte et al. [10] descreve a extensão como uma forma de produção/construção de conhecimento, a partir da experiência advinda dessa prática, sendo indissociável do processo ensino-aprendizado, pois "oportuniza ao aluno aprender a conhecer, aprender a fazer, aprender a conviver e aprender a ser”. Por meio dessa 
prática, ocorre a formação integral do futuro profissional, pois há trocas importantes do saber acadêmico na interação com a comunidade, já que insere os estudantes em todos os níveis de atenção em saúde e no ciclo de produção/construção do conhecimento. Assim, a extensão como prática realizada por cursos de graduação contribui para o processo de formação de um profissional comprometido com a realidade social $[10]$.

\section{Sobre o Curso de Nutrição}

O curso de graduação em Nutrição da Universidade de São Paulo, sediado na Faculdade de Saúde Pública (FSP), foi pioneiro no Brasil e surgiu após cinco anos da criação da própria Universidade, no então Instituto de Hygiene.

Atualmente, na FSP, são desenvolvidas diversas atividades de cultura e extensão. Nunes et al. [8] identificaram 17 atividades de cultura e extensão diferentes desenvolvidas atualmente pelos estudantes da FSP: Empresa Júnior de Nutrição (Nutri Jr.); Iniciação Científica; Associação Atlética Acadêmica XXXI de Agosto; Clínica de Atendimento Nutricional (Clinut); Jornada Universitária da Saúde (JUS); estágio curricular não obrigatório; entre outros. As autoras afirmam que a maioria das atividades é de iniciativa estudantil, apontando para a fragilidade do apoio institucional à cultura e extensão, bem como a inclusão deste tema na pauta de discussão da reformulação do projeto político pedagógico do curso de Nutrição.

Assim este trabalho teve como objetivo conhecer as percepções dos próprios estudantes do Curso de Nutrição da FSP-USP que participaram das atividades de cultura e extensão de Nutrição.

\section{METODOLOGIA}

Comprometidos com o pressuposto de que são os sujeitos para as quais se dirigem as ações os principais informantes das consequências das mesmas, optou-se por uma metodologia de abordagem qualitativa, de forma a ouvir os estudantes para compreender os valores e os significados atribuídos às experiências de extensão universitária.

De acordo com Minayo et al. [7] a pesquisa qualitativa, deve ter como preocupação compreender determinado grupo social, possibilitando a apreensão das semelhanças e diferenças em relação ao tema de estudo.

A técnica utilizada para coleta dos dados foi a de grupo focal que se aproxima de uma entrevista em grupo, mas focaliza as discussões em determinado assunto que se pretende estudar, balizada por um roteiro de questões.

Segundo De Antoni et al. [2] existem algumas vantagens na utilização dessa técnica, uma delas refere-se ao que chamaram de insight, ou seja, através de trocas de experiências e opiniões, os participantes percebem atitudes presentes em seu modo de pensar também presentes nos outros participantes; outra vantagem refere-se à possibilidade de acessar diferentes categorias sobre o estudo desejado. O que está de acordo com Iervolino e Pelicione [5], afirmando que uma das maiores riquezas do grupo 
focal é a possibilidade de construir atitudes e opiniões na interação com o outro.

A aplicação da técnica foi conduzida por um moderador e um observador, com a preocupação de promover o debate em torno de questões previamente construídas. Foram realizados cinco grupos divididos entre as atividades: Nutri Jr., Iniciação Científica, Atlética, Clinut e JUS.

Após transcrição das falas dos grupos foram realizadas leitura do material, ordenação e classificação dos dados e análise final.

\section{RESULTADOS E DISCUSSÃO}

\section{Nutri Jr.}

Trata-se de uma empresa de consultoria sem fins lucrativos, formada e administrada por alunos. Em funcionamento desde o início de 2001, a empresa presta serviços e desenvolve projetos para empresas, entidades e sociedade em geral, na área de Nutrição. Ainda, a empresa organiza atividades acadêmicas, como workshops e seminários, a fim de obter maior integração entre os meios acadêmico e empresarial.

Cada diretor fica responsável por uma diretoria: recursos humanos, marketing, relações públicas, projetos e recursos financeiros. O presidente e o vice-presidente coordenam e dão suporte a todas as diretorias. Apesar disso, as participantes contam que a direção da Empresa Jr. é plana. Embora a empresa seja dividida em diretorias, e cada um tenha uma função definida, nas reuniões gerais ocorre muita troca, a partir da expressão das opiniões individuais sobre os mais diversos assuntos.

Sobre o perfil dos participantes da Empresa Jr., os alunos destacam que aqueles que procuram a participação na mesma, de modo geral, buscam aprender e se desenvolver mais como profissionais, adquirindo experiências que promovam mudanças pessoais efetivas.

Foi questionado aos participantes sobre as motivações de cada um para participar da Empresa Jr. Uma das motivações manifestadas foi a oportunidade de entrar mais em contato com a Nutrição, o que vai ao encontro do fato de que ao longo do primeiro ano, as disciplinas cursadas são mais básicas e gerais, o que proporciona ao aluno certo distanciamento da ciência da Nutrição em si. Foi identificada como motivação, ainda, a oportunidade de aplicar a teoria na prática.

Ao serem questionados sobre a relação da atividade que desenvolvem na Empresa com outras atividades presentes no curso, os alunos relataram que nos projetos desenvolvidos é possível aplicar a teoria aprendida em sala de aula, destacando-se o fato de que nem sempre é possível aplicar a teoria da mesma forma encontrada na literatura, sendo preciso adaptá-la a realidades distintas, o que é proporcionado pela vivência na Empresa Jr.

Foi destacado que a empresa proporciona atualização profissional, apresentando temas pouco abordados na faculdade e que as pessoas que participam da Empresa desenvolvem autonomia e autoconfiança.

De forma interessante, uma aluna destacou que, não somente a Empresa Jr. de 
Nutrição, mas os demais projetos de extensão possibilitam conhecer e reconhecer as expectativas da sociedade a respeito do nutricionista, enquanto profissional da saúde. Vale destacar que foram relatadas diferenças entre os estágios curriculares e os projetos de extensão, tanto em relação ao funcionamento quanto no que diz respeito ao aprendizado e crescimento que cada um proporciona, sendo os estágios apontados como necessários, mas as atividades de extensão como fundamentais à formação pessoal e profissional dos alunos.

Os alunos pontuam, ainda, que o aluno que participa de projetos de extensão sai mais preparado da faculdade, pois tem uma experiência prévia e desenvolve habilidades no contato com as pessoas, tais como conseguir se expressar claramente. Os alunos ainda afirmaram que várias dessas habilidades não são desenvolvidas nas atividades da grade curricular, e sendo assim consideravam as atividades de cultura e extensão como fundamentais para a sua formação profissional.

Quanto a contribuição da atividade na Empresa Jr. para a vivência pessoal das participantes, foram levantados os seguintes pontos: ganho em conhecimento, aprendizados relativos ao melhor entendimento do ser humano e das relações interpessoais, respeito a opiniões diversas e agregação das mesmas em um só conceito, e desenvolvimento de uma visão ampliada sobre diferentes problemas.

Ao serem questionados sobre quais os desafios enfrentados atualmente pelo nutricionista foram apontados a desunião da classe, a valorização do profissional e o elevado número de profissionais despreparados no mercado. Destacou-se que o contato prévio com o mercado de trabalho, por meio da participação na Empresa Jr., facilita o enfrentamento de tais desafios.

\section{Iniciação Científica}

Segundo os estudantes, as razões que os levam a procurar pela Iniciação Científica (IC) são a dificuldade para conseguir estágio ou emprego, a necessidade de ocupar o tempo disponível, o interesse pela linha de pesquisa do docente em questão, a estrutura dos laboratórios da universidade, e a oportunidade de contato com a área acadêmica e com pesquisadores renomados. A dificuldade que encontram para conciliar as atividades do curso de Nutrição com uma jornada mais longa de trabalho faz com que a IC seja mais atrativa, uma vez que apresenta horários mais flexíveis.

As atividades realizadas nesta atividade de extensão, segundo os participantes do grupo focal, dependem em qual projeto de pesquisa o aluno está inscrito, mas consistem basicamente em: manutenção do laboratório e de equipamentos, análises de lâminas em microscópio, leitura de um considerável número de artigos científicos, coleta de dados e análise estatística dos mesmos. Com exceção das análises estatísticas, as demais atividades por eles realizadas não podem ser feitas por outras pessoas e todas exigem certo tempo de dedicação.

Assim como as atividades realizadas na extensão em questão, sua relação com as experiências em sala de aula irá depender de cada projeto de pesquisa. Segundo os estudantes, a IC, muitas vezes, não consegue relacionar os conteúdos aprendidos em sala de aula com a pesquisa realizada. Ao realizarem na IC o estudo de determinado 
assunto de forma específica, os alunos acabam distanciando-a da graduação, não visualizando interligação entre ambas, uma vez que na graduação o aprendizado se dá de forma abrangente. A principal relação que encontram é quando realizam a leitura de artigos científicos e conseguem compreender o que estudam nas áreas da estatística e epidemiologia.

Com relação às expectativas iniciais que os estudantes tinham em relação à Iniciação Científica, muitas coisas acabaram não correspondendo ao que esperavam. Esta extensão exige muito tempo de dedicação para que apresente resultados e às vezes a rotina acaba sendo desgastante para eles, apesar dos horários flexíveis.

Sobre a contribuição da iniciação para a formação pessoal, os estudantes afirmaram que esta exerce alguma influência, pois nela aprendem a lidar com outras pessoas e com problemas, além de melhorar sua relação interpessoal. Os alunos afirmam que, por meio desta atividade, tiveram a oportunidade de participar de congressos, aprender a apresentar seminários, debater sobre diversos assuntos e a falar em público. A leitura de artigos científicos em inglês, que é muito exigida, foi apontada como auxílio para a melhora no conhecimento desse idioma.

Segundo estes estudantes, a IC exerce influência na sua formação profissional já que os diferenciará futuramente daqueles que não a fizeram. Além disso, poderá ajudá-los a conseguir auxílio financeiro (bolsa) e entrar para o programa de pós-graduação.

\section{Atlética}

A Associação Atlética Acadêmica XXXI de Agosto é uma entidade dos estudantes de graduação da Faculdade de Saúde Pública que foi fundada em 2003, com o objetivo de promover a prática de esportes entre os estudantes, realizar e patrocinar competições e participar de jogos interacadêmicos.

Segundo os estudantes que participaram do grupo focal, os motivos que os levaram a procurar esta extensão foram: a prática esportiva, a curiosidade em conhecer a organização, o alcance de maior envolvimento com a faculdade, e a vontade de mudar o que achavam que estava errado, em lugar de eventualmente apenas criticar. Os meios pelos quais chegaram à Atlética foram o fato de conhecer outras pessoas que já participavam, o convite na recepção dos calouros e o convite de membros da Atlética realizado em outros momentos.

As atividades realizadas são a participação nos treinos de uma ou mais das quatro modalidades oferecidas ( handball, futsal, basquete e tênis) e, consequentemente, dos campeonatos que são realizados no decorrer do ano letivo. É possível também participar das atividades burocráticas da Atlética, já que esta está organizada em diferentes diretorias, contando, ainda, com um presidente e um vice-presidente, além do tesoureiro.

Para que consigam levar fundos para arcar com gastos como o transporte de alunos, compra e manutenção dos materiais esportivos, pagamento dos técnicos de cada modalidade, bem como a inscrição nos diferentes campeonatos, a Atlética realiza festas, rifas e bazares organizados pelos próprios integrantes. Ao promoverem qualquer evento dentro da faculdade, os membros da Atlética o fazem pensando nos alunos e 
em sua repercussão, colocando a ética sempre em primeiro lugar.

A relação das atividades realizadas nesta extensão com as experiências em sala de aula são encontradas principalmente no que diz respeito às atividades de falar em público e trabalhar em equipe. Em relação ao conteúdo propriamente dito, os estudantes não apontam relação com as atividades realizadas na Atlética.

No tocante às expectativas iniciais que os estudantes tinham em relação à Atlética, estes destacam terem sido alcançadas. Já sobre a contribuição da Atlética para a formação pessoal, os estudantes apontam melhora da concentração, aprendizado quanto a lidar com problemas e com pessoas, a trabalhar em equipe, a administrar projetos e horários. Além disso, participar dessa extensão parece possibilitar a socialização com alunos do próprio curso de Nutrição e de outros cursos. Segundo os estudantes, para o profissional que se tornarão e para o seu crescimento pessoal, a participação na Atlética é fundamental, pois proporciona enorme aprendizado.

\section{Clinut}

Todo aluno regularmente matriculado no curso de Nutrição pode participar do processo seletivo da Clinut. Os aprovados participam do projeto por um semestre, uma vez por semana, no Centro de Saúde Escola Geraldo Horácio de Paula Souza da Faculdade de Saúde Pública da USP.

As atividades desse projeto de extensão, segundo os participantes, começam com uma dinâmica de grupo constituída por uma aula sobre um tema de Nutrição sugerido pelas coordenadoras, seguida pelos atendimentos dos pacientes por duplas ou trios de estudantes previamente estabelecidos, pelo período de seis meses. Após o atendimento, o grupo se reúne com as nutricionistas para discutir cada caso, sendo um momento em que cada estudante coloca o problema de seu paciente e todos podem opinar e contribuir com o caso. No final do período, é feito um relatório abordando todas as questões dos pacientes e a evolução dos mesmos. Uma das críticas relatadas foi o processo de seleção dos estudantes, em que não ficaram claros os critérios de inclusão e exclusão.

Os principais motivos que levam estes estudantes a realizar as atividades oferecidas pela Clinut são: o interesse de conhecer mais a prática do nutricionista por meio do maior contato com a profissão e a busca de embasamento para ajudar na decisão da área de atuação pretendida no futuro profissional (nutrição clínica, administração de serviços, marketing nutricional ou outros). Além disso, os alunos citaram também buscar aproveitar as oportunidades oferecidas pela faculdade e incorporá-las como um diferencial na formação acadêmica.

Segundo os estudantes, as atividades desenvolvidas na Clinut se relacionam com a experiência em sala de aula de duas formas: com as disciplinas básicas, ministradas nos primeiros anos de faculdade, no sentido de ajudar a entender melhor os conteúdos; e com as disciplinas mais específicas, ministradas nos anos mais avançados de faculdade (como Dietética, por exemplo) no sentido de ajudar na elaboração dos cardápios. Essa segunda relação com a experiência em sala de aula ocorre, de modo geral, após a participação da Clinut, já que as disciplinas mais voltadas à prática profissional 
estão na estrutura curricular dos últimos semestres do curso.

Observa-se que as expectativas dos estudantes quando começaram a frequentar a Clinut foram frustradas devido à alta taxa de desistência dos pacientes, o que prejudica a evolução do atendimento e da saúde do paciente em si. Outra decepção diz respeito ao conteúdo das aulas, pois os estudantes acreditam que deveriam ter mais liberdade para elaborá-las.

Os desafios do nutricionista levantados pelos estudantes são: a inserção no mercado de trabalho, a supervalorização do médico e a falta de adesão por parte dos pacientes. Esse último desafio citado se deve à falta de valorização da profissão e ao imediatismo dos pacientes, dado que a intervenção proposta visa à mudança de hábitos alimentares a longo prazo, não apresentando, na maior parte das vezes, efeito imediato.

Essa atividade de extensão, segundo os participantes do grupo focal, contribui com a formação pessoal dos estudantes, no que diz respeito ao relacionamento profissional/paciente, já que é necessário aprender a lidar com os aspectos socioeconômicos e culturais do paciente, suas possíveis limitações intelectuais e seus hábitos alimentares. Além disso, é clara a necessidade de desenvolver a capacidade de enxergar o lado humano do indivíduo; de exercitar a paciência, dado que o nível de entendimento do paciente é diferente; mas também de adquirir segurança para transmitir o seu conhecimento.

Já as contribuições citadas pelos estudantes à formação profissional são: entender e vivenciar alguns dos desafios da prática profissional (por exemplo, a desistência dos pacientes), aprender a transmitir conhecimentos adquiridos por meio de linguagem clara e acessível, identificar problemas e propor soluções para as mais diversas situações.

JUS

A JUS envolve estudantes de diversos cursos da área de Saúde (Enfermagem, Fisioterapia, Fonoaudiologia, Medicina, Nutrição e Terapia Ocupacional), os quais interagem para o desenvolvimento de projetos que buscam melhorar a vida da população local, sobretudo relacionados à promoção e educação em Saúde. Uma mesma cidade é visitada por três anos consecutivos, cumprindo as seguintes etapas: no $1^{\circ}$ ano, identificar os problemas locais, destacando as principais necessidades da população; no $2^{\circ}$ ano, intervir, baseando-se na análise dos dados obtidos no ano anterior, com foco nos agentes multiplicadores a fim de tornar o projeto autossustentável na cidade; e no $3^{\circ}$ ano, avaliar os resultados e propor à prefeitura local, planos para melhorar o sistema de saúde e melhorar a qualidade de vida da população.

A JUS é coordenada por estudantes representantes de cada curso envolvido na jornada. No curso de Nutrição, iniciou-se a execução de um processo seletivo para participação na JUS a partir de 2009, com a redução do número de vagas reservadas aos alunos de Nutrição.

Os estudantes participantes reúnem-se e começam a planejar e desenvolver suas atividades propostas à comunidade no primeiro semestre. A viagem dura cerca de nove dias, sendo que os estudantes ficam alojados em um espaço cedido pela 
prefeitura, a qual também se responsabiliza pelo fornecimento da alimentação aos estudantes. Durante a jornada, são elaborados relatórios discutindo o desenvolvimento das atividades realizadas, com a descrição das dificuldades e acertos de cada atividade realizada com a população atendida. Ao término da jornada é feita uma avaliação geral pelos coordenadores, de forma a ser elaborado um relatório, posteriormente encaminhado para a prefeitura como uma devolutiva que possa contribuir na continuação das atividades iniciadas pelos estudantes.

Os estudantes relataram desenvolver atividades de intervenção para diferentes grupos da população, divididos em grupos de atuação dentre os cursos que participaram da JUS. Foram feitas pesquisas de campo, nas quais foram incluídos inquéritos alimentares para conhecer as características da comunidade local. Além disso, os estudantes promoveram uma campanha que abordou assuntos como diabetes, hipertensão, vacinação, tabagismo. Segundo os estudantes, o projeto de extensão tem caráter de prevenção e promoção da saúde e não de assistência, configurando-se mais adequadamente como um trabalho de educação em saúde.

Segundo os estudantes, os meios pelos quais souberam a respeito da jornada foram: palestras, semana de recepção dos calouros, e apresentação da JUS em sala de aula. Já os motivos da procura pela JUS foram: ter contato com pessoas que precisam de ajuda; viver e intervir sobre uma realidade diferente; e levar um pouco do conhecimento adquirido e acumulado na universidade às populações mais carentes, sendo essa atividade de extensão encarada como uma enriquecedora experiência universitária.

É muito interessante notar que os estudantes têm a percepção de que as populações às quais pretendem ajudar acabam por ensinar muito mais sobre a vida do que os próprios estudantes sobre qualquer questão técnico-científica, devido à realidade na qual estão inseridos. Segundo eles, o contexto no qual se insere a JUS não é apenas uma questão acadêmica, mas também uma questão de cidadania, dado que passa pela preocupação com os demais seres humanos, o que contribui largamente para a formação pessoal dos estudantes. Por todas essas razões, os estudantes relataram ter suas expectativas de participação da JUS largamente superadas.

Segundo a opinião dos entrevistados, é dada pouca atenção à questão de segurança alimentar e nutricional no curso de Nutrição, e a JUS, como projeto de extensão, é uma alternativa que supre essa carência do curso, já que desperta os alunos para a responsabilidade de fazer com que as pessoas tenham acesso ao direito à alimentação, contribuindo para a aproximação dos estudantes com a realidade da fome e a falta de acesso aos alimentos.

No que diz respeito aos desafios atuais do nutricionista, os estudantes apontam a desmistificação da imagem de que o nutricionista é o profissional que sempre vai impor regras, limitando o prazer das pessoas; o estímulo à mudança de hábito de vida das pessoas; e a adequação das orientações nutricionais à realidade da população atendida. Ressaltam, ainda, que provavelmente o maior desafio do nutricionista é intervir no processo de políticas públicas para que a fome seja eliminada.

A reflexão de como o conhecimento teórico compartilhado em sala de aula poderia ser transmitido para a população, segundo os estudantes, somente ocorre entre 
os participantes dessa atividade de extensão. Dessa maneira, ressalta-se a importância da contribuição da JUS na formação dos estudantes, visto que essa atividade de extensão aproxima os estudantes da realidade.

\section{DISCUSSÃO}

A partir das informações coletadas nas falas dos alunos, fica claro que, de modo geral, os alunos consideram as atividades de extensão como ferramentas fundamentais no enriquecimento de sua formação pessoal e profissional, ainda que cada tipo de extensão tenha maior enfoque em alguns tipos de habilidade e competências, cumprindo, assim, com alguns dos objetivos principais das atividades de cultura e extensão apresentadas pela USP.

Corroborando este ponto de vista, Erdmann et al. [3] relataram em seu trabalho, realizado com alunos do curso de Enfermagem, que as atividades de extensão preparam o aluno de graduação de maneira eficaz e fazem com que o mesmo desenvolva competências diferenciadas, principalmente quando comparado àqueles alunos que não participaram desta experiência. Segundo este autor, a extensão auxilia a formação de um profissional ético e que tem a capacidade de aprender constantemente.

Tavares et al. [12] encontraram a aquisição de maior experiência clínica e um melhor currículo como principais motivações de estudantes de Medicina da Universidade Federal de Minas Gerais ao buscarem as atividades de extensão. Tais motivações se refletem principalmente entre os alunos que buscam a Clinut como atividade de extensão.

Ribeiro [11] observa cada vez mais as expectativas dos estudantes que se integram às atividades de extensão, sendo uma delas o compromisso com a saúde coletiva. Ponte et al. [10] relatam que a extensão propicia a integração de estudantes com a comunidade e contribui para o processo de formação profissional dos mesmos. Tais achados vão completamente ao encontro do relato dos alunos que participam da JUS, principalmente no que diz respeito ao papel social da atividade, principalmente considerando que, segundo os estudantes, a extensão deveria ser um retorno da universidade à sociedade.

Foi discutido também que um dos propósitos da extensão é justamente saber quais são as deficiências da população e a partir daí pesquisar e investir em educação para melhorar a situação encontrada. Segundo os estudantes, um dos propósitos das atividades de extensão é mostrar à sociedade, de diferentes formas, que a universidade é de todos.

Segundo Freire, citado por Franco e Boog [4], a prática realizada dentro dos projetos de extensão, no momento em que o aluno entra em contato com a comunidade, possibilita a construção de conhecimento crítico quando ele é estimulado a realizar o movimento dialético do abstrato ao concreto. Essas autoras citam também Turato, que discute que essa articulação de saberes se estabelece em uma aliança com a comunidade, tendo como base a perspectiva de elaboração de novos projetos em comum. Paralelamente, Ribeiro [11] também ressalta a importância da extensão para a formação dos acadêmicos de Fisioterapia, no sentido de lhes possibilitar uma aproximação com a realidade social da população, estabelecendo vínculos com as pessoas 
e organizações da comunidade, pautados no diálogo e na responsabilidade social.

Quanto à comparação das atividades de extensão aos estágios curriculares, Amorim et al. [1] expõem que, na maioria das vezes, as atividades de estágio acontecem no último ano da graduação e, considerando que esse é o primeiro e único momento de aproximação da teoria com a prática, há dificuldade da realização de redirecionamentos dos conteúdos trabalhados desde o primeiro ano do curso para a aplicação no campo de trabalho. Um dos papéis positivos das atividades de extensão mais frequente e intensamente levantados pelos estudantes foi justamente a possibilidade de contato com a prática profissional do nutricionista desde o primeiro ano de faculdade.

Franco e Boog [4] recomendam que seja estimulado, desde o início da formação, o desenvolvimento de responsabilidades e reconhecimento da importância das disciplinas de cunho social e educativo, como um dos aspectos inerentes à prática profissional.

O enfrentamento da complexidade exige pensar "a sinergia, a orquestração de recursos cognitivos e afetivos diversos para enfrentar um conjunto de situações" [9]. Nesse contexto, essa vivência poderia ser uma diretriz do curso de graduação como um todo já que Franco e Boog [4] discutem que a realidade da vida e das situações a serem enfrentadas na profissão não pode ser simplificada e reduzida a questões que se resolvem dentro de uma ou outra disciplina.

Na perspectiva dos estudantes, portanto, o ambiente de sala de aula não é visto como um espaço para a organização daqueles recursos cognitivos e afetivos para enfrentamento de situações tão complexas como aquelas vivenciadas no contexto das atividades de extensão.

\section{CONCLUSÃO}

A partir da análise dos relatos, pode-se concluir que as atividades de cultura e extensão são importantes ferramentas para desenvolver habilidades para a prática profissional. Neste sentido, é fundamental evidenciar os projetos político-pedagógicos dos cursos, principalmente, da área da Saúde, que encontrem formas de flexibilizar a estrutura curricular para inserção de atividades de cultura e extensão universitária.

\section{REFERÊNCIAS}

[1] AMORIM, S. T. S. P.; MOREIRA, H.; CARRARO, T. E. A formação de pediatras e nutricionistas: A dimensão humana. Rev. Nutr., v. 14, n. 2, pp. 111-118, ago. 2001.

[2] DE ANTONI, C.; et al. Grupo focal: Método qualitativo de pesquisa com adolescentes em situação de risco. Arquivos Brasileiros de Psicologia, v. 53, n. 2, pp. 38-53, 2001.

[3] ERDMANN, A. L. et al. Vislumbrando o significado da iniciação científica a partir do graduando de enfermagem. Esc Anna Nery Rev. Enferm., v. 14, n. 1, pp. 26-32, jan.-mar. 2010. 
[4] FRANCO, A. C.; BOOG, M. C. F. Relação teoria-prática no ensino de educação nutricional. Rev. Nutr., v. 20, n. 6, pp. 643-655, 2007.

[5] IERVOLINO, A. S.; PELICIONI, M. C. F. A utilização do grupo focal como metodologia qualitativa na promoção da saúde. Rev. Esc. Enf. USP, v. 35, n. 2, pp. 115-121, 2001.

[6] LARROSA, J. Tecnologias do eu e educação. In: Silva, T. T. (org.) O sujeito da educação: Estudos foucaultianos. Petróplois: Vozes, pp. 35-84, 1994.

[7] MINAYO, M. C. S.; ASSIS, S. G.; SOUZA, E. R. Avaliação por triangulação de métodos: Abordagem de programas sociais. Rio de Janeiro: Fiocruz, 2005.

[8] NUNES, N. M.; et al. Atividades de cultura e extensão na FSP-USP e o perfil dos alunos. In: $17^{\circ}$ Simpósio Internacional de Iniciação Científica da USP; Ribeirão Preto, BR, 2009. Anais. São Paulo, 2009.

[9] PERRENOUD, P. Ensinar: Agir na urgência, decidir na incerteza. Porto Alegre: Artes Médicas Sul, 2001.

[10] PONTE, C. I. R. V.; et al. A extensão universitária na Famed/UFRGS: Cenário de formação profissional. Rev. Bras. Educ. Med., v. 33, n. 4, pp. 527-534, 2009.

[11] RIBEIRO, K. S. Q. S. A experiência na extensão popular e a formação acadêmica em fisioterapia. Cad. Cedes, Campinas, v. 29, pp. 335-346, 2009.

[12] TAVARES, A. P.; et al. O "currículo paralelo" dos estudantes de medicina da Universidade Federal de Minas Gerais. Rev. Bras. Educ. Med., v. 255, pp. 254265, 2007.

[13] USP - Universidade de São Paulo. Pró-Reitoria de Cultura e Extensão. Resolução no 4940, de 26 de junho de 2002. D.O.E. - 03 jul 2002

ANA MARIA CERVATO-MANCUSo docente do Departamento de Nutrição da Faculdade de Saúde Pública da USP (FSP-USP) - e-mail: cervato@usp.br

NADINE MARQUES NUNES nutricionista e mestranda da Faculdade de Saúde Pública (FSP-USP)

ELISABETE AGRELA DE ANDRADE psicóloga e doutoranda da Faculdade de Saúde Pública (FSP-USP) 